\title{
Contra la violencia, educación popular y ciudadanía global
}

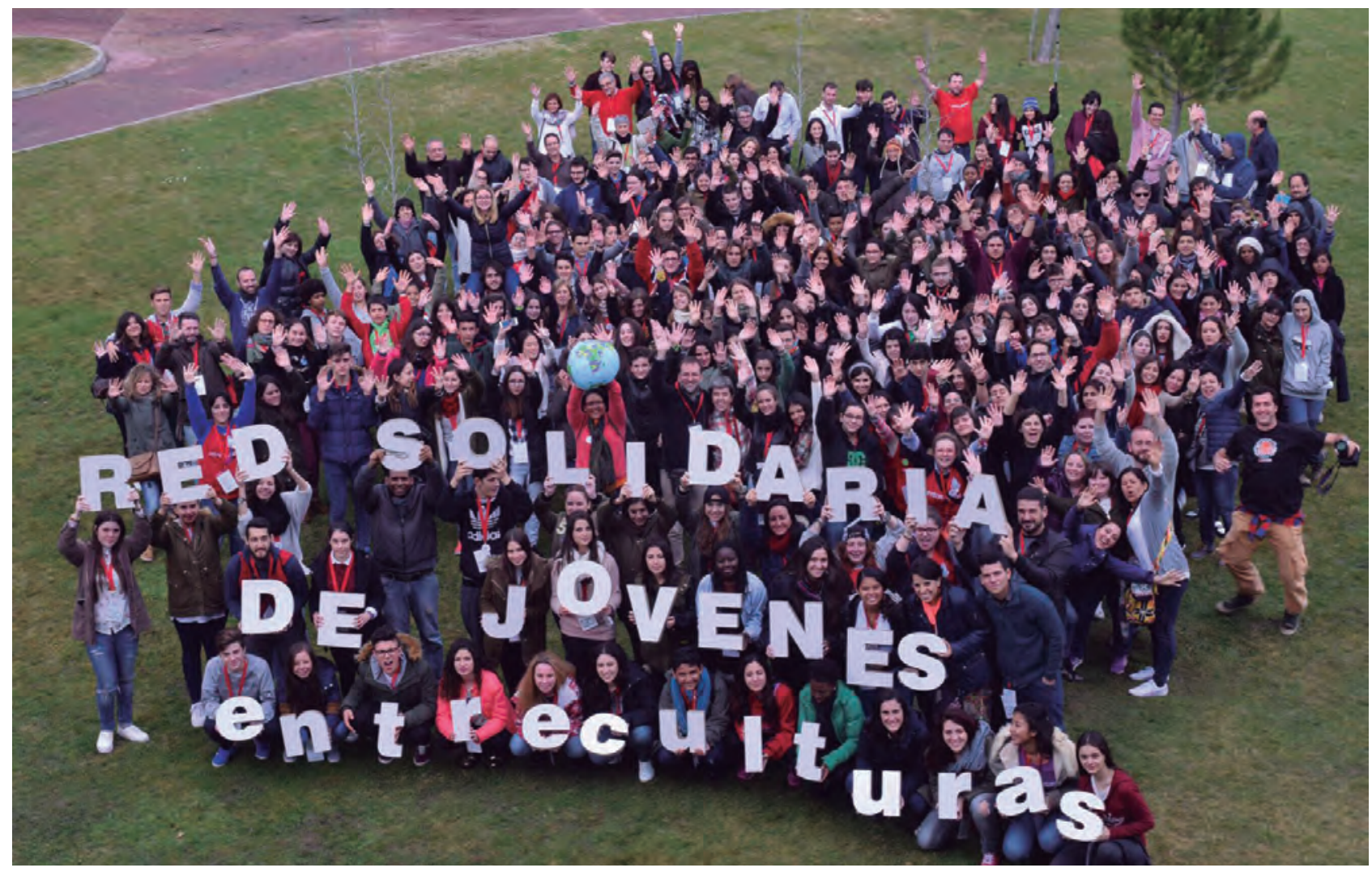

Desde 2014 a 2017 Fe y Alegría Nicaragua y Entreculturas (Fe y Alegría en España) llevaron a cabo un proyecto educativo conjunto con el objetivo de dar respuesta a las situaciones de violencia que viven los adolescentes estudiantes de secundaria en sus entornos cercanos, con especial atención a la violencia entre iguales o bullying pensando globalmente y actuando localmente. Una experiencia que dejó huella tanto en las personas como en los centros que participaron en ambos países.

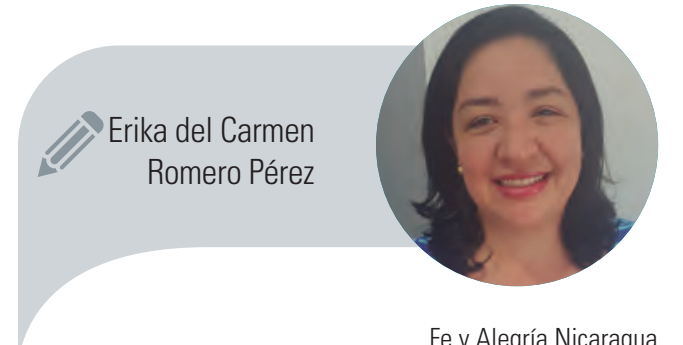

erika.romero@feyalegria.org.ni

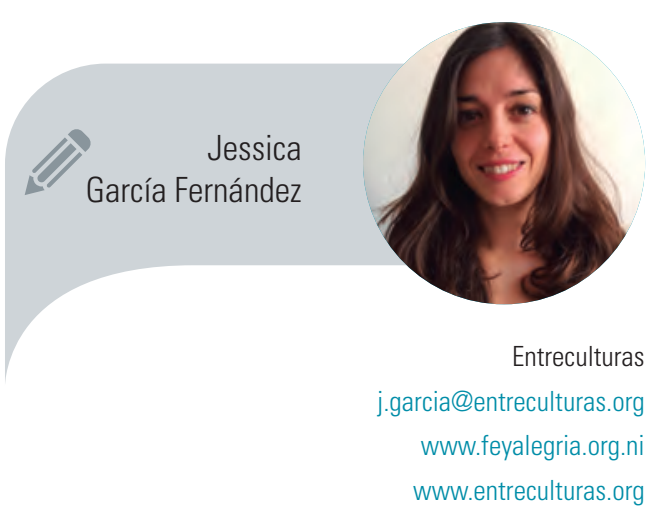


Cuando emprendas tu viaje a Itaca pide que el camino sea largo, lleno de aventuras, lleno de experiencias. Ten siempre a Itaca en tu mente. Llegar allí es tu destino. Más no apresures nunca el viaje. (...) Aunque la halles pobre, Itaca no te ha engañado. Así, sabio como te has vuelto, con tanta experiencia, entenderás ya qué significan las Itacas.

Constantino Cavafis

En un momento histórico de cambio de época, en el que la humanidad busca maneras de afrontar los desafíos de la desigualdad, la pobreza, la violencia y la destrucción del medio ambiente, todo apunta a la necesidad de construir un nuevo modo de relacionarnos. Es el momento de revisar los modos en los que se ejerce el poder, poniendo la dignidad humana en el centro y construyendo en torno a la misma un modelo de sociedad global inclusiva y equitativa.

Desde Entreculturas pensamos que la educación es una de las herramientas claves en este camino. Siguiendo un modelo pedagógico que une la educación para la ciudadanía global, el paradigma pedagógico ignaciano y la educación popular, desarrolla el programa Entrescuelas en el marco de la Red Solidaria de Jóvenes de Entreculturas.

Entrescuelas pone en conexión a adolescentes y docentes de España y de otros países en los que Entreculturas está presente. Es una oportunidad de vivir experiencias de encuentro intercultural y de ciudadanía global a partir de la participación en proyectos educativos conjuntos.

El programa abarca distintos tipos de proyectos que, sobre la base de unos principios comunes, se diseñan con la participación de educadores de todos los países implicados, de forma que sean significativos en los distintos contextos socioculturales.

En clave de ciudadanía global, busca que adolescentes y jóvenes:

入 Amplíen su visión del mundo enriqueciéndola con los puntos de vista que cada quien trae de su contexto.

入 Construyan una narrativa común sobre nuestra sociedad global. $\boldsymbol{\lambda}$ Tomen conciencia de que pueden contribuir a cambios globales asumiendo compromisos en sus entornos cercanos.

त Se sientan parte de una juventud mundial comprometida con la solidaridad y la justicia.

$\boldsymbol{\lambda}$ Establezcan relaciones horizontales de respeto y amistad.

En la actualidad se desarrollan tres tipos diferentes de propuestas, que irían de menos a más en nivel de intensidad 1) trabajo en campañas compartidas 2) propuesta de formación conjunta y 3) creación de acciones conjuntas.

En este último grupo, encontramos uno de los proyectos que más impacto ha tenido en jóvenes y docentes y que culminó el pasado agosto. Tras más de tres años de trabajo conjunto entre grupos de adolescentes estudiantes de secundaria en Galicia, Andalucía y Nicaragua, cuatro jóvenes y dos docentes españoles, representantes de estos grupos, viajaron a Nicaragua. El tema común la prevención de la violencia y especialmente el bullying, como una de las formas más comunes de violencia entre los más jóvenes. Un año y medio antes, estos grupos de adolescentes habían acogido la participación de representantes nicaragüenses en un encuentro internacional que Entreculturas organizó en España.

\footnotetext{
Hay experiencias que te cambian la vida y te hacen replantearte quién eres y qué tienes en este mundo. El 18 de agosto de 2017 me tocó a mí vivir esa experiencia viajando a Nicaragua, un país situado en Centroamérica.
}

$$
\text { Claudia }
$$

(16 años, joven participante Entrescuelas)

\section{Nicaragua: una apuesta por la adolescencia y la juventud}

En Nicaragua viven más de seis millones de personas, su capital es Managua y aunque en el país se encuentran algunas de las grandes fortunas, su índice de desarrollo humano la sitúa como el país más pobre de América Latina, después de Haití. 
el proceso por un educador o educadora del centro escolar. Cada participante del grupo firmó su propia carta de compromiso que incluía la autorización de sus familias y la información del centro.

La propuesta, en el marco teórico-práctico de la educación popular, se llevó a cabo siguiendo la metodología FormAcción desarrollada por Fe y Alegría.

FormAcción combina la realización de sesiones presenciales de formación y reflexión, con la puesta en práctica de compromisos y acciones concretas en la vida cotidiana. Por otra parte, los propios grupos de adolescentes participantes en el proyecto replican las sesiones con pares en sus centros, convirtiéndose así en facilitadores del proceso para sus compañeros y compañeras. Desde este enfoque es fundamental que el aprendizaje se desencadene a partir de la propia experiencia, tomando conciencia de cómo viven la violencia de forma personal, en sus familias, en sus centros educativos, en sus barrios, en sus países y en el mundo.

El proceso de FormAcción se desarroIla través de diferentes actividades divididas en las siguientes etapas: sensibilización, concientización, empoderamiento, organización y movilización.

En cada una de las etapas, la dinámica se estableció de la siguiente forma:

Sesiones dinamizadas $>$ Trabajo de grupo $>$ Intercambio virtual

Siguiendo este orden las sesiones dinamizadas sirvieron para presentar y preparar el trabajo de cada etapa realizando las explicaciones necesarias para la comprensión de los objetivos y contenidos que se iban a trabajar en esa etapa. Estas sesiones dinamizadas duraron entre hora y media y dos horas y se realizó al menos una por etapa.

En cada sesión, se pautó un trabajo posterior que el grupo realizó de forma autónoma y acompañada en el ámbito de su centro escolar o entorno social.

Dentro de estos grupos se instauraron comisiones de trabajo con tareas concretas, definidas por los y las jóvenes. Estos son algunos ejemplos:
Objetivo: darnos cuenta de la importancia de ser adolescentes y jóvenes sensibilizados como ciudadanos desde la realidad de pobreza y violencia de los barrios o comunidades

\begin{tabular}{|c|c|c|c|}
\hline Tiempo & Tema/ Actividad & Desarrollo & Recursos \\
\hline 20 & \multirow{3}{*}{$\begin{array}{l}\text { Somos } \\
\text { adolescentes } \\
\text { y jóvenes } \\
\text { sensibles a los } \\
\text { problemas de la } \\
\text { comunidad }\end{array}$} & $\begin{array}{l}\text { Reflexión sobre mi experiencia / } \\
\text { trabajo individual } \\
\text { y Lo que me gusta y lo que no } \\
\text { me gusta de mi barrio } \\
\text { y ¿Qué hacen los adolescentes } \\
\text { y jóvenes en el barrio? } \\
\text { y ¿Qué hacen las mujeres? } \\
\text { У Frente a los problemas de la } \\
\text { comunidad ¿cuál es la actitud } \\
\text { común de los jóvenes? }\end{array}$ & $\begin{array}{l}\text { У Fotocopia con } \\
\text { preguntas } \\
\text { У Lapiceros }\end{array}$ \\
\hline 30 & & $\begin{array}{l}\text { Intercambiar con otros: } \\
\text { compartir el trabajo realizado en } \\
\text { grupos de } 5 \text { personas y preparar } \\
\text { una expresión creativa sobre lo } \\
\text { que dialogamos (pintura, poesía, } \\
\text { canción, sociodrama, etc.) }\end{array}$ & $\begin{array}{l}\text { У Papelógrafos } \\
\text { y Colores } \\
\text { y Marcadores } \\
\text { y Maskintape }\end{array}$ \\
\hline 25 & & $\begin{array}{l}\text { Plenario: } \\
\text { presentación creativa }\end{array}$ & \\
\hline
\end{tabular}

Programa FormAcción. Etapa de empoderamiento (Act. 2)

\begin{tabular}{|c|c|c|c|}
\hline Tiempo & Tema/ Actividad & Desarrollo & Recursos \\
\hline 35 & Debate & $\begin{array}{l}\text { Se invita al grupo a poner sus } \\
\text { diferentes puntos de vistas ante } \\
\text { las siguientes afirmaciones: } \\
\text { y Yo soy un hombre joven/una } \\
\text { mujer joven y tengo poder } \\
\text { de dominio sobre otros } \\
\text { compañeros y sobre las } \\
\text { mujeres. } \\
\text { ע La fuerza y el poder de } \\
\text { dominar me hacen sentirme } \\
\text { más hombre o más mujer. } \\
\text { Yi poder está al servicio } \\
\text { de otros y otras, mi poder } \\
\text { es para crear para generar } \\
\text { buenas relaciones. } \\
\text { yengo el poder de dialogar, } \\
\text { de entender los puntos de } \\
\text { vista diferentes a los míos, } \\
\text { de llegar a acuerdos. } \\
\\
\text { La facilitadora cierra este espacio } \\
\text { explicando que cada uno de } \\
\text { nosotros tenemos un poder, un } \\
\text { poder de decir sí, un poder para } \\
\text { actuar, un poder para dañar } \\
\text { o ayudar a otros y nuestras } \\
\text { acciones y decisiones pueden } \\
\text { afectarnos de manera personal o } \\
\text { pueden afectar a otros. }\end{array}$ & $\begin{array}{l}\searrow \text { Papelógrafo } \\
\text { ע rotuladores }\end{array}$ \\
\hline
\end{tabular}

入 Animación: animar y alegrar cada taller preparando y coordinando dinámicas y juegos que rompan el hielo y logren un ambiente relajado y animado. 


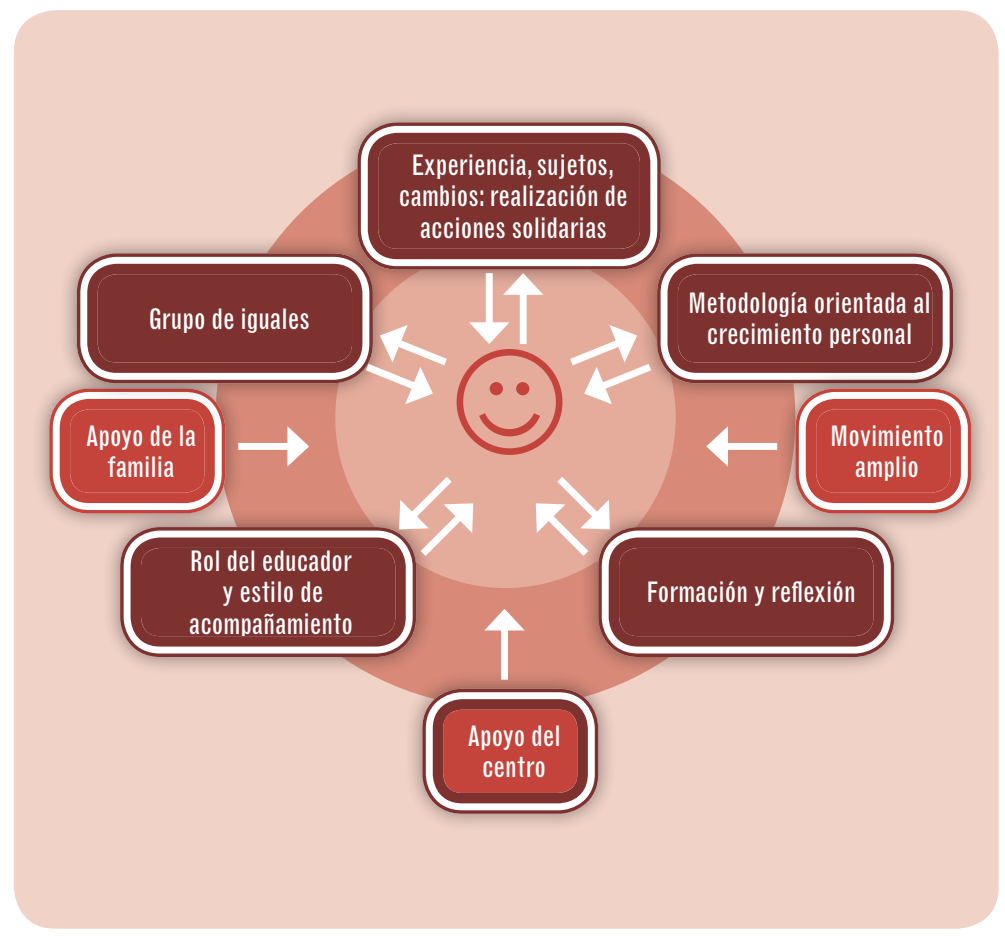

入 Reflexión/memoria: tomar nota de lo trabajado en cada taller (conclusiones, opiniones del grupo, frases curiosas...) e introducir el siguiente taller recordando a todos lo trabajado en el anterior. Para hacerlo de forma dinámica y creativa pueden trabajar con la comisión de animación.

入 Comunicación: tienen varias funciones:

1. Sacar fotos durante los talleres y de los trabajos que se hagan.

2. Realizar algún vídeo.

3. Participar activamente -aunque debemos hacerlo todos- en el grupo de Facebook, colgando cosas como: conclusiones de los trabajos, fotos de las reuniones, etc. Su función es comunicar todo lo que se haga hacia fuera (así que jimaginación al poder!).

Una vez finalizada cada etapa se producían los intercambios virtuales para compartir lo aprendido y trabajado con los grupos participantes de ambos países. En estos intercambios iban tomando conciencia de que, aun siendo parte de realidades tan diferentes, sus problemas eran muy similares. Comprendían que la violencia es un reto global y que ellos estaban dando respuesta desde su acción concreta en el entorno cercano que, sumada a las de sus compañeros en los centros de sus países, o al otro lado del océano, generan una corriente de cambio mucho más amplia. Se trata en definitiva de vivir el clásico lema de la educación para la ciudadanía global "piensa globalmente, actúa localmente", a partir del encuentro y de la amistad. Para jóvenes y adolescentes los lazos emocionales entre pares son detonantes fundamentales del cambio personal.

Este proceso se complementó con dos viajes presenciales. Uno en el mes de febrero de 2016, cuando representantes de los grupos de liderazgo juvenil de Nicaragua viajaron a Galicia donde compartieron actividades con los grupos de los centros educativos participantes en el proyecto, además de participar conjuntamente en el V Encuentro Global de la Red Solidaria de Jóvenes de Entreculturas.

El proyecto culminó con el viaje del grupo español a Nicaragua en agosto de 2017. Estos intercambios tal y como se recoge en la sistematización del programa Entrescuelas, son clave para el logro de los objetivos del programa.

\section{Resultado: dejar huella}

Los cambios que ha provocado en este programa en todos y cada uno de sus participantes nos hablan del despertar de una mirada nueva y de un hacer diferente. La experiencia no está exenta de dificultades y retos, pero su huella es permanente.

Hago y comparto estas reflexiones desde la fe y la alegría, desde el agradecimiento y la esperanza, desde la distancia ya cercana. Fe en que el viaje, encuentro y experiencia se me ofreció como regalo para aprender "algo" que aún no termina de desvelarse. Alegría de haber vivido un sueño de juventud (18-20 años) que me permitió recuperar, revitalizar y actualizar conceptos (de pedagogía popular de P. Freire, de pedagogía y teología de la liberación F. Cardenal, de L. Boff, de poesía E. Cardenal), prácticas (trabajo en equipo, colaborativo, confianza, democracia compartida...), miradas (hacia los que están donde termina el asfalto...) y sentimientos (esperanza, urgencia...) que tenía olvidados. Aprendí que Fe y Alegría es un proyecto educativo, pero también una dinámica, una manera de acercarse a la gente, a la realidad y descubrir posibilidades diferentes de trabajar y vivir.

JUAN DE LA FUENTE

(Docente acompañante del proceso Entrescuelas) 
Podemos destacar algunas iniciativas concretas que ya están en marcha tanto en Nicaragua como en los centros de España que participaron.

Se han desarrollado las denominadas Comisiones de Convivencia, cuyo objetivo es visibilizar el trabajo de estos grupos de jóvenes en la prevención de la violencia. En estas comisiones se inserta además la figura del mediador o mediadora juvenil, figuras de referencia ante la aparición de conflictos en el aula.

Asimismo, estás Comisiones de Convivencia han recopilado cuentos elaborados por el alumnado, han realizado foros, debates y convivencias lúdicas escolares para prevenir la violencia por medio de relaciones respetuosas entre pares. En alguno de los centros se han instalado buzones para facilitar que cada estudiante pueda compartir su experiencia, realizar propuestas o denunciar situaciones de abuso o violencia.

También este proceso ha dejado valiosas lecciones para docentes y acompañantes, puesto que les ha permitido identificar que creer en las capacidades de los adolescentes, es fundamental para lograr cambios duraderos.

Este programa ha conseguido unir a personas de países y culturas diferentes en torno a la violencia como problemática común, permitiéndoles conocerse, respetarse, crear vínculos de amistad y admiración mutua, compartir propuestas, dificultades y esperanzas. Ese caminar conjunto es la Ciudadanía Global.

Somos la levadura que levanta la masa. FyA Nicaragua es educación, es la levadura que levanta la masa, que

\section{HEMOS HABLADO DE}

\section{Educación global; violencia; paz; jóvenes adultos; bullying.}

Este artículo fue solicitado por PADRES Y MAESTROS en septiembre de 2017, revisado y aceptado en diciembre de 2017.

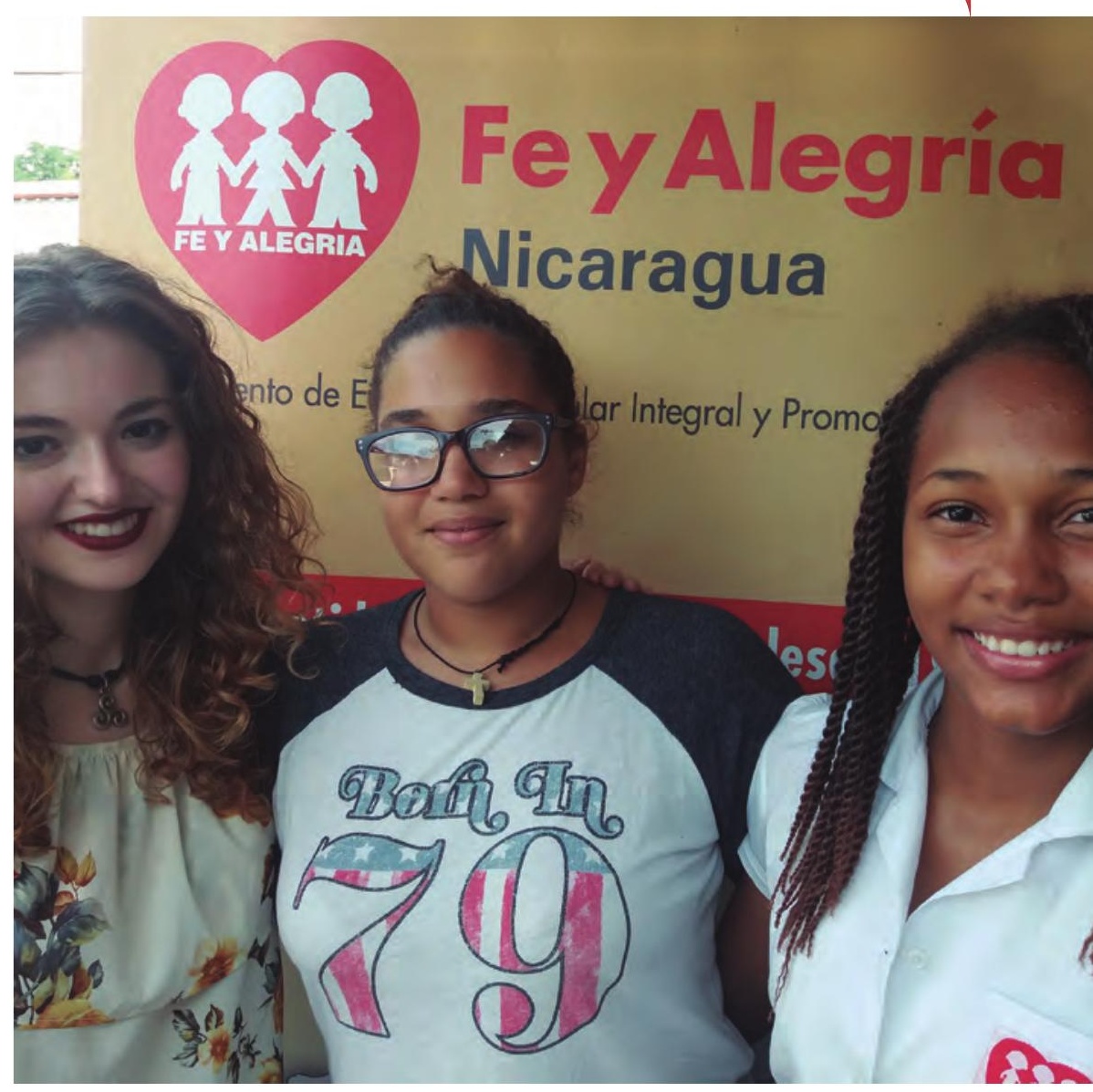

mueve y crea personas que se han propuesto cambiar el mundo. En este viaje he aprendido que nunca estarás sola, como Maldita Nerea cantaba, nombrando el eco que hoy te envuelve, ese eco que conforma el movimiento de personas, el eco de tus pasos, de tu movimiento. $Y$ sí, las personas tenemos un fin, y algún día llegará el mío. Mi objetivo es que mis actos queden en el recuerdo de las personas, y ser en ellas, parte del cambio, que fue y es para mí esta experiencia: dejar huella.

\section{Rosalía}

(17 años, joven participante Entrescuelas)

\section{DARA SABER MÂS}

EntreCUlturas. (2018). Un mundo de encuentros. Recuperado de: https://www.entreculturas.org/es/publicaciones/un-mundo-deencuentros

EntreCulturas. (2017). Día Internacional de la niña 2017. Recuperado de: https://www.entreculturas.org/es/publicaciones/dia-internacional-de-la-nina-2017

Entreculturas. (2015). Promoviendo el cambio global desde la educación. Recuperado de: https://www.entreculturas.org/es/publicaciones/promoviendo-el-cambio-global-desde-la-educacion-0 